\title{
A RELAÇÃO COMPLEXA ENTRE O SERVIÇO SOCIAL NO CONTEXTO DA SAÚDE E O USO DA INTERSETORIALIDADE
}

\author{
THE COMPLEX RELATION ENTERS THE SOCIAL WORK IN THE CONTEXT \\ OF THE HEALTH AND THE USE OF THE INTERSECTORAL
}

\author{
Patricia Barreto Cavalcanti ${ }^{1}$ \\ Erica Fernanda Torres Macedo ${ }^{2}$
}

\begin{abstract}
RESUMO
Este artigo objetiva contribuir para a construção do conhecimento acerca da estratégia da intersetorialidade, particularmente em relação à produção científica em desenvolvimento na área do Serviço Social. Partimos do pressuposto de que este dispositivo de gestão vem frequentemente sendo tomado como principal mecanismo de gestão das políticas públicas, nomeadamente as políticas de proteção social no Brasil. Contrariamente, os estudos sobre este entorno ainda se mostram incipientes em relação aos mais variados processos de implementação de planos, programas e projetos vinculados ao sistema protetivo nacional com tímida alteração no que concerne a operacionalização do Sistema Único de Saúde. Por conseguinte, quando nos reportamos para as reflexões teóricas sobre o uso dos arranjos intersetoriais no interior das ações profissionais dos Assistentes Sociais do campo da assistência pública à saúde, a escassez de referenciais teóricos sugere que a categoria precisa se debruçar sobre os vieses desta questão, sobretudo por se constituir num dos núcleos profissionais que mais possui potência em disparar ações intersetoriais, fundamentalmente pela formação generalista que recebe. Assim, este estudo procurou refletir quais os limites que se interpõe a prática do Assistente Social do campo da saúde na tessitura de arranjos intersetoriais a luz da produção teórica constante nos principais canais de circulação da produção científica do Serviço Social Brasileiro.
\end{abstract}

PALAVRAS-CHAVE: Intersetorialidade. Serviço Social. Política de Saúde. Saúde.

\begin{abstract}
This objective work to contribute for the construction of the knowledge concerning the strategy of the intersectoral, particularly in relation to the scientific production in development in the area of the Social Work. We leave nominated of estimated of that the this device of management comes frequent being taken as main mechanism of management of the public politics, politics of social protection in Brazil. Contrarily, the studies on this surrounding still reveal incipient in relation to the most varied entailed processes of implementation of plans, programs and projects to the national protective system with shy alteration with respect to operationalization of the Only System of Health. Therefore, when in

\footnotetext{
${ }^{1}$ Doutora em Serviço Social/PUC-SP, Professora Associado IV do Departamento de Serviço Social da UFPB, Bolsista de Produtividade em Pesquisa nível 2 do CNPQ. Telefone 83 32266001. E-mail: patriciabcaval@gmail.com.

${ }^{2}$ Mestre em Serviço Social/UFPB Especialização em Saúde Pública / FACISA 2010 Assistente Social do HC/UFPE. E-mail: ericapires@hotmail.com.
} 
we report them for the theoretical reflections on the use of the intersectoral arrangements share winthin professional actions of the Social Assistants of the field of the public assistance to the health, the scarcity of theoretical referential suggests that the category necessary if to lean over on the biases of this question, over all for if constituting in one of the professional nuclei that more possess power in going off intersectoral actions basically, of the generalist formation that receives. Thus, this study it looked for to reflect which the limits that if the light of the constant theoretical production in the main canals of circulation of the scientific production of the Brazilian Social Service interposes practical of the Social Assistant of the field of the health in the contexture of intersectoral arrangements.

KEYWORDS: Intersectoral. Social Work. Health politic. Health.

\section{INTRODUÇÃO}

Desde o princípio desta pesquisa, levada a cabo pelo Setor de Estudos e Pesquisas em Saúde e Serviço Social da UFPB, partimos da ideia de que na nossa sociedade as questões que circunscrevem sua dinâmica são de uma complexidade infindável. Sua compreensão exige um esforço de apreensão da totalidade. Daí a preocupação de superar o isolamento disciplinar, setorial e criar conhecimento e estratégias articuladas. A partir daí percebemos que da forma como as gestões governamentais tem se apresentado e proposto suas ações, as quais não dão conta de responder e reverter às situações de pobreza e desigualdade social, o coletivo da sociedade tende a apresentar-se insatisfeito e queixoso diante da resultante das políticas sociais. Neste ponto, dar-se uma das várias oportunidades de inserir esta temática no cenário das políticas sociais e do Serviço Social.

Os resultados ora apresentados são produtos de um projeto integrado de pesquisa intitulado "Serviço Social, Política de Saúde e Intersetorialidade: repercussões, desafios e perspectivas para o Assistente Social na atenção básica. Trato-se pois, de resultados obtidos através de uma investigação teórica, baseada no método dialético, que privilegiou a noção de totalidade, na qual consideramos as questões de ordem ídeopolítica, socioeconômica e técnico- operativa que configuraram a trajetória do Serviço Social no campo da saúde, bem como, a história da assistência pública à saúde no Brasil, notadamente em relação ao uso da estratégia da intersetorialidade.

No decurso do procedimento metodológico ocorrido em junho e julho de 2014, foram utilizadas as pesquisas bibliográfica e documental, seguindo os parâmetros que cercam o processo da leitura reflexiva, para coleta e posterior tratamento das produções científicas constantes nos anais do Encontro Nacional de Pesquisadores em Serviço 
Social, no período de 2001 a 2012, bem como dos artigos científicos de revistas Qualis A e B da área de Serviço Social.

\section{INTERSETORIALIDADE NAS POLÍTICAS SOCIAIS: NOVAS}

\section{POSSIBILIDADES DE GESTÃO}

Durante nossa incursão teórica sobre a intersetorialidade identificamos diversos pontos de vista e inúmeras áreas nas quais o tema tem sido tratado assumindo, portanto vieses diferentes.

Há segundo os estudiosos uma polissemia acerca da temática, o que implica seu tratamento a partir de variáveis diversas. Alguns autores a relacionam com a gestão pública, articulando-a a outra estratégia de gestão, qual seja a descentralização. Outros por sua vez introduzem o conceito da interdisciplinaridade para melhor compreende-la. Há ainda aqueles que investigam a intersetorialidade a partir do paradigma da promoção da saúde e do princípio da integralidade ou mesmo tendo como cotejo a concepção de pobreza. O fato é que esse tema tem se constituído num dos pontos principais das agendas de investigação e trabalho junto as políticas públicas e a gestão pública, na perspectiva de que as políticas públicas, sobretudo as de corte social sejam mais abrangentes e se pautem por características mais universalistas e inclusivas.

Essa vasta produção tem início na década de 1980 tendo como indutores as características das políticas sociais brasileiras, historicamente sobrepostas e com pouca resolutividade, bem como, as inovações advindas da Constituição de 1988, que produziu inovações na gestão dessas políticas face a ampliação legal dos direitos sociais.

Com base neste entendimento, identifica-se que um dos grandes desafios é romper com a tradição da ciência moderna, que opera com uma lógica parcializada de organização e produção do saber, tendo como consequência uma intensa especialização disciplinar e práticas sociais fragmentadas. Nesta direção, diversos autores assinalam a importância de buscar no paradigma da interdisciplinaridade uma análise global dos problemas e na estratégia de gestão intersetorial a promoção de práticas sociais mais eficazes em relação à questão social atual.

Autores como Sposatti (2006), Inojosa, Junqueira, Bronzo (2010), Monnerat (2009, 2011), dentre outros, vem desde este período adensando as proposições teóricas sobre a intersetorialidade, com intuito de contribuir para sua efetivação. 
Uma das áreas que mais tem produzido conhecimento acerca das possibilidades e limites da intersetorialidade como estratégia de gestão é a Administração Pública. A produção de conhecimento desta área é vasta e se acosta principalmente nas ideias de Inojosa (1997); Junqueira (1997) que fazem a articulação dessa categoria aos propósitos da gestão pública, notadamente a gestão municipal.

Nessa direção, Junqueira, Inojosa e Komatsu (1997, p. 24), tratam a intersetorialidade em sua aproximação, com o tema da descentralização. Relatam esta aproximação quando a descentralização é compreendida “como a transferência do poder de decisão para as instâncias mais próximas e permeáveis a influencia dos cidadãos” e a intersetorialidade corresponde ao "atendimento das necessidades e expectativas destes mesmos cidadãos de forma sinérgica e integrada”. Daí a articulação entre ambos compor um novo modelo de gestão pública.

Esta discussão apresentada pelos autores também levanta questões como território regional e redes de ação social, já que a intersetorialidade para se concretizar na gestão pública, necessita além de um contexto democrático, portanto, descentralizado, (no qual a partilha de poder e responsabilidades estejam em curso) da adscrição territorial. A premissa é de que é no território que as expressões da questão social ganham mais visibilidade, induzindo o modelo de gestão das políticas sociais a um contato mais direto com o real, com as demandas advindas de um território que possui singularidades e não de pressuposições teóricas (SPOSATTI, 2006).

Por outro lado, Inojosa (2001, p. 105) apresenta uma discussão importante sobre a intersetorialidade e a transdisciplinaridade, ou seja, uma reflexão sobre a complexidade e diversidade das necessidades sociais e o modo separado, isolado com que as gestões públicas tem tentado responder as necessidades de prover qualidade de vida e superar as questões sociais. Destaca que "uma perspectiva de trabalho intersetorial implica mais do que justapor ou compor projetos que continuem sendo formulados e realizados setorialmente”. Não trata de ações pontuais, dirigidas por sujeitos de boa vontade, implica numa perspectiva muito maior que traz impacto na ação do Estado.

A autora ressalta ainda, que no seu entender, existem quatro aspectos básicos para se trabalhar a partir de uma perspectiva de transetorialidade/ intersetorialidade, São eles: mudança de paradigma; projeto político transformador; planejamento e avaliação participativos e com base regional; e atuação em rede de compromissos. Daí por diante 
ela vai traçando o modo de fazer a intersetorialidade a partir destes quatro pontos relevantes a seu ver.

1. Mudança de paradigma. Que seria uma mudança de perspectiva, de postura, perceber as coisas, as pessoas e suas necessidades, numa ótica de complexidade. E assim superar a fragmentação disciplinar que fragiliza a compreensão e promover uma conversação, diálogo entre os saberes e/ou setores.

2. Projeto político transformador. A realidade de políticas sociais verticalizadas, piramidais, sobrepondo ações não consegue articular-se a proposta intersetorial, de diálogo, de parceria, troca de saberes, rompendo com políticas assistencialistas que reforçam o sistema vigente e sua cartografia.

3. Planejamento e avaliação participativos e com base regional. Este terceiro ponto, adentra as organizações administrativas, pois trata de uma proposta de planejamento diferenciada nas dinâmicas que considera a localidade e faz parte permanente no processo, digo, "análise de situação, passa por escolhas estratégicas e faz acordo.” Também é fundamental que este planejamento seja participativo, agregando atores sociais e perspectivas diversas de perceber e identificar o problema.

4. Atuação em rede de compromisso social. No quarto e ultimo aspecto a autora continua pontuando mudanças organizacionais. Que não são mudanças isoladas, que não interferem em nada. É uma mudança para atuar em rede de compromisso social, onde o Estado permite o trabalho com outros atores sociais de organizações diversas e que de uma forma coletiva mobilizem-se para juntos trabalharem um determinado problema. Essa estrutura não comporta setores isolados e ações fragmentadas.

Uma das principais observações sobre este autora é que ela raciocina na perspectiva de como fazer para trabalhar com intersetorialidade, ou seja, como construir o trabalho intersetorializado.

Uma das contribuições mais relevantes para o adensamento da temática foi construída por Bronzo (2010) quando a autora constrói sua análise sobre a intersetorialidade a partir de seu uso no enfrentamento a pobreza. Ao analisar a categoria “pobreza”, a autora mencionada articula como aspectos relevantes, a compreensão de sua multicausalidade, do território onde ela se expressa. Ela parte da Serv. Soc. \& Saúde, Campinas, SP v.14, n. 2 (20), p. 187-210, jul./dez. 2015 ISSN 1676-6806 
tese de que o processo de utilização dos arranjos intersetoriais devem ser sistemáticos e concretizados em vários planos da gestão, em muitas dimensões, desde a articulação e coordenação de estruturas setoriais (planejamento) até a implementação das ações, o que ela nomeia como arranjos de alta e baixa densidade.

Sua concepção de intersetorialidade prevê um modelo de gestão “multinível” que por vezes demandam transformações no escopo institucional ou mudanças nos vieses organizacionais, introduzindo inovações como gestão em rede, adscrição territorial ou mesmo possibilidades técnico-profissionais como o apoio matricial.

Ainda na direção do arcabouço teórico que cerca a intersetorialidade, temos a contribuição de Pereira (2011) sinalizando que essa estratégia deve está ancorada numa perspectiva interdisciplinar, ou seja, ao utilizarmos a estratégia é necessário a postura de estar aberto a outros campos de saberes.

A mesma autora indica ainda que a adoção do mecanismo intersetorial e sua defesa, não significa a negação dos espaços setoriais (em se tratando de políticas públicas), mas, fundamentalmente da adoção de diálogo entre os setores. Acrescenta ainda, que para além de um recurso técnico gerencial, a intersetorialidade é antes de tudo um ato político, pois depende da vontade política dos atores envolvidos na sua utilização.

Nas produções recentes, diante do arcabouço normativo que permeia todo o rol de políticas sociais, há um esforço em analisar como as ações estão se refletindo nas condições objetivas de vida da população. A intersetorialidade entra em cena com a perspectiva de conjugar as políticas sociais, para que num dado espaço seja possível alcançar o indivíduo de forma totalizante e assim reproduzir ou generalizar a experiência para raios de abrangência maiores.

As questões sociais apresentadas na atualidade exigem uma integralidade de ações com vistas a atingir um resultado efetivo. Devido esta compreensão é indispensável perceber que problemas de saúde, por exemplo, demandam ações de vários níveis de políticas setoriais para serem solucionadas em toda sua dimensão.

Neste caso, se a abordagem não for integral e cada política não for acionada e prestar serviços resolutivos, certamente resultará numa intervenção sem efeito nas raízes do problema. Entretanto, superar a fragmentação do processo é uma das dimensões da intersetorialidade. É pré-condição o planejamento, como diretriz para pensar ações de qualidade e que atinjam seus objetivos. 
Deste modo o planejamento, como processo que parte da análise da situação até a intervenção final e coletiva é uma implicação para as ações intersetoriais nas políticas públicas. Um planejamento participativo, onde o Estado é um co-participante que realiza pactos com a percepção de outros segmentos.

A proposta é uma nova organização para superar o parcelamento das estruturas governamentais e seus equipamentos. É preciso decisão política para repaginar a velha organização, que reforçam determinadas estruturas de poder. A integração entre as políticas sociais é um imperativo para a materialização dos direitos sociais.

Há ainda uma produção bastante densa no campo da saúde coletiva que articula o uso da intersetorialidade a busca da resolutividade das demandas em saúde, tendo como parâmetro a promoção da saúde e o conceito do processo saúde-doença resignificado pela Organização Mundial em Saúde em 1948.

Essa nova perspectiva de compreender o processo de adoecimento ou não adoecimento, amplia o horizonte de como as ações públicas devem ser tratadas e aproxima necessariamente a noção de intersetorialidade e a centralidade desta discussão no âmbito da política. Assegurando que por si só esta política não dá conta de sua demanda e objetivo. Ao contrário, invoca a necessidade de responder a diversas demandas sociais (ANDRADE, 2004; MIOTO e SCHUTZ, 2010).

É possível identificar que o setor saúde tem uma percepção mais restrita e/ou específica sobre o tema. Sua preocupação surge de seus próprios interesses, que busca a resolução de seus problemas a partir de articulação e apoio de outros setores. A sinergia, neste caso, funciona para resolução de questões complexas de saúde.

Em contrapartida a recomendação da OPAS - Organização Pan-Americana em Saúde é que este setor esteja também receptivo a convocatória de outras políticas (COSTA et al.).

O Novo pacto federativo com a promulgação da Constituição Federal de 1988, resultado de um processo constituinte de negociação, participativo e propositivo, pautado num estatuto de direitos democráticos apresentou uma possibilidade diferenciada de proteção social. Uma proteção social capaz de entender e considerar as desigualdades sociais de forma complexa e numa perspectiva de totalidade, reconhecendo o cidadão na sua integralidade e acionando de forma articulada as políticas e os direitos sociais. Uma nova forma de abordagem e articulação das necessidades da população. 
Este entendimento sobre proteção social consolidou uma grande mudança no âmbito das políticas sociais. O imperativo de promover políticas públicas integradas. Esta mudança, considerável, de que tratamos, aparece na Constituição no seu artigo 194 e leva o nome de Seguridade Social e apresenta-se assim descrito: “A seguridade social compreende um conjunto integrado de ações de iniciativa dos poderes públicos e da sociedade, destinadas a assegurar os direitos relativos à saúde, à previdência e à assistência social” (BRASIL, 1998, p. 131).

Neste caso, ao adotar a noção de Seguridade Social o pacto federativo aumenta a responsabilidade do Estado e incorpora novos direitos sociais e entende a mesma, como um conjunto de ações de participação governamental e/ou não, objetivando a assegurar os direitos às políticas do tripé.

Apesar do histórico descompasso entre as gestões, e a configuração social contraditória, é possível identificar que a despeito de representar um desafio para as políticas sociais, a integralidade tem sido perseguida quando se acreditam nas premissas da luta constituinte e na perspectiva de integralidade para a realidade da proteção social.

Desta forma, pautamos a necessidade de qualificar as políticas na contramão da fragmentação, desarticulação e minimização que impossibilitam a dada integralidade na atenção da proteção social. Na contemporaneidade das políticas sociais brasileiras, o que podemos perceber, diante da realidade das práticas profissionais é que cada política coordena sua ação individualmente, o que não permite alcançar a verdadeira resolução das questões apresentadas, pois, o usuário dos serviços/cidadão não é acolhido em sua totalidade, e que consequentemente este usuário sai do serviço com a sensação de insatisfação e decepção.

Os resultados desta fragmentação são diariamente percebidos pelos profissionais da base dos serviços públicos: O assistente social, por exemplo, em uma unidade de emergência e trauma, identifica que o trabalho da equipe multidisciplinar perde efetividade quando após o tratamento emergencial o usuário não tem uma moradia em condições adequadas para acolhê-lo em um pós-operatório, quando também a unidade de saúde mais próximo de sua residência não tem profissional que possa acompanhar o caso, quando a previdência social não dá respostas adequadas para possibilitar a subsistência durante a recuperação. Neste caso, nem o assistente social, nem qualquer outro membro da equipe tem acesso ao sistema setorizado e condições de encaminhar resolutivamente tais demandas. Fica a sensação de impotência. 
De acordo com Junqueira, Inojosa e Komatsu (1997) “As estruturas setorizadas tendem a tratar o cidadão e os problemas de forma fragmentada, com serviços executados solitariamente, embora as ações se dirijam à mesma criança, à mesma família, ao mesmo trabalhador e ocorram no mesmo espaço territorial e meio ambiente” (ibid., p. 22). Caminhando assim para ações desarticuladas e que não conseguem atingir a integralidade do ser social.

Daí a evocação do significado da intersetorialidade para as políticas sociais. A Intersetorialidade tem surgido como uma alternativa a insatisfação correspondente à fragilidade das práticas do Estado, uma contraposição ao aparato setorizado.

Segundo Andrade (2004) um dos fatores mais complicados em trabalhar a intersetorialidade pertence ao nível de complexidade embutido na sua operacionalização, pois, implica na superação de uma constituição do Estado que foi hegemônica durante todo o século XX. Esse modelo setorizado é representado pelo autor por um conjunto de casinhas paralelas e responsáveis individualmente cada qual pela sua área de atuação, digamos políticas, onde cada qual responde as demandas particularmente.

O surgimento da intersetorialidade como um contraponto a esta realidade setorizada é vista por nós, como um processo político de pactuações. E essa integração entre as políticas públicas é um indicativo para a consolidação dos direitos sociais.

É importante destacar que essa discussão sobre a intersetorialidade, surge mundialmente, no âmbito da saúde. Em um período histórico de mudança social significativa, com o processo de industrialização e o estouro das cidades. Um momento de urbanização sem precedentes e na falta de planejamento e de estrutura das cidades.

Este momento de capitalismo industrial apresenta, necessariamente, uma preocupação de como manter o alto número de produção e a força de trabalho mínima para o não comprometimento dos lucros, ou seja, foi no interior das intencionalidades e tencionalidades do sistema capitalista vigente que os grupos de interesse europeus passaram a se preocupar com a situação saúde da população operária e fazer suas primeiras relações com as condições de vida desta população. Passou-se a relacionar o processo de adoecimento às condições de moradia, sanitária, alimentação, trabalho, dentre outras.

A discussão surgiu articulada ao movimento de Reforma Médica Alemã (posteriormente Medicina Social) e as apreciações sobre os determinantes sociais da saúde. Entretanto, foi uma discussão pautada na concepção de que o modelo Serv. Soc. \& Saúde, Campinas, SP v.14, n. 2 (20), p. 187-210, jul./dez. 2015 ISSN 1676-6806 
estritamente biológico não dá conta da problemática. Reconhecendo que “a promoção da saúde demanda uma ação coordenada entre diferentes setores sociais, ações do Estado, da sociedade civil, do sistema de saúde e de outros parceiros intersetoriais” (ANDRADE, 2004, p. 50).

Como temos observado a abordagem da intersetorialidade tem sido diversificada. Segundo Monnerat (2009), as produções na administração pública, percebem a intersetorialidade como uma estratégia inovadora de gestão das cidades, capaz de formular e implementar políticas sociais de forma singular, potencializando ações que superam a lógica fragmentada e pontual para responder as questões oriundas das necessidades dos cidadãos. Também nesta abordagem, está presente a preocupação com os recursos humanos e financeiros e sua otimização.

Do ponto de vista da Política de Saúde, o modo como foi conduzida desde 88, não priorizou o fortalecimento de um sistema de Seguridade Social. O que em nosso entender teria reforçado a ideia de intersetorialidade pautada na proposta sanitarista.

Parte considerável da produção teórica desta área concebe a intersetorialidade a partir de uma perspectiva bastante específica. Uma visão endógena que compreende a intersetorialidade a partir da articulação de diversos setores para atingir resultados eficazes em saúde. Ou seja, o problema inicial a ser solucionado parte da necessidade da área de saúde, a qual demanda de outros setores sua colaboração para resolução de problemas específicos de sua política. Segundo a definição a OMS - Organização Mundial de Saúde a intersetorialidade é compreendida como uma articulação de ações de vários setores para alcançar melhores resultados em saúde de uma maneira mais efetiva, eficiente ou sustentável do que poderia alcançar o setor saúde agindo por si só.

Em contrapartida a OPAS - Organização Pan-Americana recomenda que a ação intersetorial demande da área da saúde não somente iniciativa, mas receptividade a convocatória de outros setores.

Entretanto é possível identificar na literatura que a preocupação atual do setor saúde com a promoção de políticas intersetoriais pode ser percebida na tentativa de revitalização do debate sobre os determinantes sociais do processo saúde/doença e o resgate de princípios fundamentais do projeto de reforma sanitária: descentralização, promoção da saúde, integralidades, participação/ controle social. Segundo Mioto e Nogueira (2009), é importante destacar que a intersetorialidade é um dos pilares estruturantes da integralidade. Essa integralidade é um grande desafio a medida que se observa que a realidade brasileira é de políticas fragmentadas e desarticuladas. 
Do ponto de vista da Política de Assistência Social a intersetorialidade é identificada como uma estratégia de gestão preconizada na política. E apesar disto ainda encontra-se em uma fase de construção e amadurecimento. A literatura indica que apesar de estar preconizada na formulação dos principais programas ainda tem dificuldade de funcionar satisfatoriamente.

Se acresce o fato da Política de Assistência Social ainda não ter conseguido alcançar a consolidação ídeo-política necessária e ao eleger os arranjos intersetoriais como um dos dispositivos fundamentais de implementação vem enfrentando diversos entraves, seja pela influência já destacada do modelo cartesiano de formular políticas públicas no Brasil, seja, pelo histórico que a antecedeu, onde as ações assistenciais eram marcadamente clientelistas.

\section{SERVIÇO SOCIAL, SAÚDE E INTERSETORIALIDADE NA PRODUÇÃO DO CONHECIMENTO}

Partindo do entendimento de que a intersetorialidade é "a articulação de saberes e experiências com vistas ao planejamento, para a realização e avaliação de políticas, programas e projetos, com o objetivo de alcançar resultados sinérgicos em situações complexas” (INOJOSA, 2001, p. 105). Trata-se de buscar um esforço coordenado de vários órgãos, setores, saberes na realização de uma ação planejada com intuito de alcançar um objetivo coletivo, "mais do que justapor ou compor projetos” criar uma nova dinâmica e postura de trabalhos e gestão para enfrentar o coletivo.

Na contribuição de Junqueira (1999),

A intersetorialidade constitui uma concepção que deve informar uma nova maneira de planejar, executar e controlar a prestação de serviços para garantir o acesso igual dos desiguais. Isso significa alterar toda forma de articulação dos diversos segmentos da organização governamental e dos seus interesses (Ibid., 1999, p. 27).

Com base no que foi dito, o autor reforça que é necessário articular saberes e setores para alcançar resoluções das questões complexas da realidade social. Significa trabalhar a totalidade das necessidades de forma articulada e integral.

No contexto particular da saúde, o debate se dá inicialmente nos pressupostos das determinações sociais do processo de vida e adoecimento, que passa a ser considerado a partir de um conjunto articulado de fatores como trabalho, lazer, 
educação, habitação, saneamento, alimentação, bem como da promoção à saúde que preconiza a ação de diversos setores de forma coordenada, priorizando a vida com qualidade ao contrário da falta de doenças. Essa formulação propõe responsabilidade conjunta de diversos atores.

Neste caso, para garantir o direito à saúde, as necessidades sociais devem ser supridas de forma integral, em sua totalidade e complementaridade, por isso, seu atendimento por posturas profissionais acríticas e estanques é ineficiente. Assim intersetorialidade é considerada uma construção necessária na medida em que se opõe a tal postura. É nesta direção que ela tem sido evocada nas políticas de Saúde (MIOTO; SCHUTZ, 2009).

Segundo Mioto e Nogueira (2009, p. 231), é dentro da perspectiva,

[...] da adoção dos determinantes sociais como estruturantes dos processos saúde-doença, que as ações profissionais dos assistentes sociais podem ter maior centralidade, assinalando um novo estatuto ao serviço social no campo da saúde.

Atuando nos três níveis de complexidade em saúde, o profissional de Serviço Social tem conseguido historicamente se consolidar como um núcleo profissional essencial no processo de assistência à saúde. A prática profissional que inicialmente se pautou em fundamentos teórico-metodológicos conservadores, tem se apresentado nas últimas décadas no campo da saúde com traços propositivos e vieses críticos.

Apesar de não ter tido uma participação efetiva na luta pela construção do Sistema Único de Saúde brasileiro em meio ao movimento sanitário da década de 1970, consegue enquanto categoria profissional levantar o debate no interior da profissão sobre a necessidade de contribuir para a efetivação ao direito a saúde, no processo de implementação do SUS na década de 1990.

Assim, a profissão chega à década de 1990, em geral, desarticulada ou pouco articulada ao Projeto de Reforma Sanitária e sendo demandada segundo Bravo e Matos (2009) por um lado para ações sem reflexão, individuais, fiscalizadoras, assistencialistas e de seleção socioeconômica; e de outro para uma ação mais crítica em busca da democratização do acesso a serviços e informação, incentivo a participação, numa perspectiva interdisciplinar.

Chegamos ao século XXI, com uma realidade problemática no que diz respeito à própria política de saúde e o exercício profissional do serviço social.

Uma conjuntura que retrata a saúde de forma precarizada com hospitais superlotados, usuários hospitalizados em corredores e acomodados em colchões ao Serv. Soc. \& Saúde, Campinas, SP v. 14, n. 2 (20), p. 187-210, jul./dez. 2015 ISSN 1676-6806 
chão, falta de material e medicamentos, profissionais insuficientes e insatisfeitos, filas enormes para marcação de consultas, horas de espera para atendimento, falta de recursos financeiros e investimentos, maioria dos serviços montados em sistemas de plantão, privatizações e desresponsabilização do Estado sobre as políticas sociais, ampliação de serviços sem critérios prévios, fenômeno da judicialização da saúde.

Ao profissional tem sido demandado efetivar direitos em tempos de grande crise, pois diante desta realidade é quase que regra para os assistentes sociais não conseguir mediar de fato à inacessibilidade aos direitos dos usuários da saúde, não construir práticas intersetoriais na saúde, não conseguir contribuir efetivamente para elevar a qualidade do atendimento e realizar atendimento humanizado.

Por sua vez, a questão decisiva que se coloca para os assistentes sociais, diante desta complexidade, é que:

As bases teórico-metodológicas são recursos essenciais que o Assistente social aciona para exercer o seu trabalho [...] o conhecimento não é só um verniz que se sobrepõe superficialmente à prática profissional, podendo ser dispensado; mas é um meio pelo qual é possível decifrar a realidade e clarear a condução do trabalho a ser realizado (IAMAMOTO, 2000, p. 63).

Alguns autores tem tratado a intersetorialidade diante das práticas profissionais, como é o caso de Costa (2010) que tem trabalhado a temática a partir da prática e contribuições dos profissionais do Serviço Social no âmbito do SUS.

De acordo com a autora, a intersetorialidade deve ser compreendida de uma forma ampliada, planejada e desenvolvida coletivamente, num processo democrático de participação. Também que é preciso despojamento de amarras individuais de saber e disposição para construção coletiva. É uma estratégia ampla de gestão que não desconsidera as contribuições dos diversos sujeitos coletivos.

Ressalta que “[...] do ponto de vista da organização dos serviços, exige esforços de construção de uma organização matricial que perpassa tanto o espaço da macropolítica quanto o da micro-política dos processos de trabalho em saúde” (COSTA, 2010, p. 219). Um dos achados de sua pesquisa retrata que embora venha sendo percebida como de fundamental importância nas respostas às inúmeras fragilidades sociais, a intersetorialidade não foi estabelecida como estratégia de gestão e planejamento das políticas sociais brasileiras.

Neste caso inclui-se em mais uma fragilidade na gestão da política de saúde e na estratégia do nosso Sistema de Saúde. O que nos aponta , segundo Costa (2010), a Serv. Soc. \& Saúde, Campinas, SP v.14, n. 2 (20), p. 187-210, jul./dez. 2015 ISSN 1676-6806 
dificuldade de incorporar a concepção ampliada de saúde e retrata a organização fragmentada e setorizada do trabalho em saúde: a influência exercida pela lógica privatista e biomédica na rede de atendimento, priorizando ações e práticas pontuais, curativas e em contrapartida as de prevenção e promoção de saúde.

Neste caso, como perscruta a autora, “[...] a intersetorialidade não constitui objeto do conjunto das práticas em saúde e, como não pode ser absolutamente ignorada, vem sendo tratada como atividade de uma profissão” (COSTA, 2010, p. 219).

Em sua maioria estas demandas intersetoriais extrapolam a proposta do equipamento de saúde e seus parâmetros de produtividade, ou seja, das diversas determinações sociais que escoam, em seu ponto alto, para o SUS, são encaminhadas e incorporadas pelo Serviço Social. Tais demandas demonstram que muito do que se chega à política de saúde são expressões de diversas naturezas e deveriam ser atendidas numa perspectiva integral e em articulação com as políticas de assistência social, previdência, educação. “Trata-se de um trabalho ainda restrito ao espaço da micropolítica do processo de trabalho em saúde, basicamente orientações, encaminhamentos e/ou articulações” (COSTA, 2010, p. 221).

Ainda que de forma inicial, pontual existem esforços de planejar, pactuar e combinar ações de modo sustentável. Afirma que, este processo vai além de meros encaminhamentos, são frutos de negociação em equipe e contatos diversos. E observa que quando as ações são levantadas e tratadas em grupo nos espaços de negociação, tem a possibilidade de efetividade. No entanto, majoritariamente as ações são individuais e imediatas. Na realidade, o Serviço Social tem realizado estas ações/atividades de cunho intersetorial, a partir dos conhecimentos e bagagem adquiridos ao longo de sua prática histórica na área da saúde. Acrescenta que as demandas de viés intersetorial encaminhadas por diversos atores sociais ao Serviço Social, representa o reconhecimento de que, operacionalmente, a intersetorialidade é uma estratégia necessária a respostas das iniquidades sociais.

De acordo com o que nos é pontuado pela autora, o conjunto das articulações do serviço social, é o movimento de esforços para a garantia de direitos, num Estado de mínimas responsabilidades e comprometimento com a população cidadã. Adverte ainda que, esse processo contribuiria muito mais, se os profissionais da saúde, destacadamente os assistentes sociais sistematizassem este trabalho, com suas demandas, compreensão, encaminhamentos e resolutividade. Por fim, salienta que este material deve ser utilizado para subsidiar argumentos e articulações em prol da implementação da estratégia da Serv. Soc. \& Saúde, Campinas, SP v. 14, n. 2 (20), p. 187-210, jul./dez. 2015 ISSN 1676-6806 
intersetorialidade na política de saúde e nas gestões das demais políticas públicas; no aprofundamento das elaborações sobre os determinantes sociais do processo de adoecimento; potencializar os movimentos reivindicatórios. A não sistematização reduz o potencial acumulado.

"Na condição de mera atividade, as ações intersetoriais não tem avançado na superação do conjunto das ações fragmentadas, ao contrário têm se ajustado a tal fragmentação, suprindo lacunas de tal processo" (COSTA, 2010, p. 227). A construção desse movimento é complexa e envolve pactuações diversas, e essas últimas não dispensa seus embates e a exposição das perspectivas diversificadas. Também não dispensa a disponibilidade de compartilhar, despojar e construir poder e saber.

A autora defende que, na prática, o profissional que mais contribui para construção dos arranjos intersetoriais dentro da política de saúde são os assistentes sociais por sua formação mais crítica e generalista. Que têm maior capacidade de identificar dentro do espaço profissional as oportunidades de articulação para efetivamente atender o usuário numa perspectiva de integralidade dentro da proteção social.

Já no estudo de Amaral (2007), com assistentes sociais da alta complexidade em saúde, a questão era refletir sobre a intersetorialidade a partir da necessidade de responder, de modo integral, as demandas complexas que chegam aos serviços de urgência e emergência. Identificou que a intersetorialidade acontece em três níveis de articulação setorial na saúde, no âmbito da formulação; âmbito da gestão; e âmbito de execução dos serviços. Aponta que, no âmbito da assistência à saúde, identificou que as atividades intersetoriais também podem ser classificadas em três grupos:

1. “ações que desenvolveram articulações dentro do próprio hospital”;

2. “ações que exigiram articulação no âmbito do sistema de saúde”;

3. Ações que exigiram articulações com outras políticas públicas” (AMARAL, 2007, p. 62).

As práticas intersetoriais dos assistentes sociais neste território, funciona como o de um agente que articula, integra e dá unidade ao todo, passando pelas diversas instancias de funcionamento do equipamento e seus membros, e extrapolando para as diversas políticas públicas. Tendo como objetivo deste movimento, a resposta adequada a uma perspectiva de atendimento baseada na integralidade e no reconhecimento, da necessária compreensão sobre a importância dos determinantes sociais do processo de adoecimento e recuperação. (AMARAL, 2007) 
O que sugere que o profissional domine todo fluxo do serviço hospitalar, as instancias de resolução, e prestação de serviços, de toda rede de proteção social, demais instituições e organismos de possível acesso pelos usuários. Ainda que tenha as informações pertinentes aos direitos e como acessá-los em toda rede pública existente (AMARAL, 2007).

Vemos por sua vez, mais detalhadamente em Schutz (2009), a intenção de perceber a intersetorialidade no campo dos serviços e a contribuição que pode ser dada pelos assistentes sociais na construção da intersetorialidade. A partir de sua pesquisa com assistentes sociais de Florianópolis, percebe que há entre os profissionais uma dificuldade de reconhecer a intersetorialidade em suas ações devido à própria fragmentação da rede, somado a isso elas usam rotineiramente essa estratégia e naturalizam essa prática sem a reflexão devida. Esse movimento é resultado da deficiência teórica acerca do tema na formação, assim como a dificuldade de entender a intersetorialidade a partir de um único conceito.

A dificuldade de concretizar a intersetorialidade nos serviços se dá a partir das disputas dos profissionais em busca dos seus espaços e a centralização dos atendimentos; hierarquização excessiva, burocratização dos serviços, que por não ser articulado onera as famílias que buscam o atendimento de suas demandas pelas diversas instituições e devido ao patrimonialismo e a personificação dos serviços (SCHUTZ, 2009).

O assistente social é a porta de entrada dos serviços de saúde, para responder as demandas buscam as redes de serviços e as informações sobre o funcionamento desses, é imprescindível sua qualificação assim como a realização de uma leitura crítica da realidade e a documentação dos atendimentos através de protocolos. Ao sistematizar esses atendimentos enquanto demanda coletiva, tem maior poder para pressionar os gestores das políticas sociais a fim de que a intersetorialidade aconteça a partir da gestão e também de acionar as instâncias de controle social (SCHUTZ, 2009).

Em Schutz (2009) é defendida a ideia de que a maior contribuição que o Serviço Social dá ao debate da intersetorialidade se embasa na perspectiva da totalidade social, pois percebe os usuários como cidadão de direitos e suas necessidades devem ser atendidas, na perspectiva da integralidade, o que pressupõe intersetorialidade.

As autoras supra analisadas, nos serviram de lastro teórico para o procedimento de análise dos trabalhos científicos pesquisados e arrolados na pesquisa. 
Dentre os achados mais gerais da pesquisa, observamos que há uma predominância de artigos científicos nas revistas consultadas, que articularam o estudo da intersetorialidade ao processo operacional das políticas sociais. Tal fato é natural em função das características de inserção profissional que acompanham a profissão de Serviço Social no Brasil, desde a sua gênese. É notório que os espaços sócioocupacionais dos assistentes sociais são majoritariamente as políticas de natureza social, isso inclusive sendo enfatizado no Código de ética profissional no Título II, art. $2^{0}$ que se refere à participação na elaboração e gerenciamento das políticas sociais, e na formulação e implementação de programas sociais.

Regulamentado pela Lei n. 8.662 de 1993 e por um Código de Ética Profissional (1993), o Serviço Social apresenta-se na cena contemporânea como uma profissão analítica e interventiva, com uma série de atribuições e competências fundadas na garantia de direitos sociais e na construção de uma sociedade verdadeiramente democrática, sem preconceitos e iniquidades sociais. Na perspectiva de atenção integral em saúde, as demandas sociais emergem de várias formas no cotidiano do trabalho do Assistente Social. Comumente exigem a intervenção profissional na viabilização do acesso a consultas, exames, internações e tratamentos (LANZA et al., 2012, p. $6)$.

Detectamos ainda, poucas produções em forma de artigos que vinculam a estratégia da intersetorialidade ao plano mais geral das políticas públicas e o fazem num escopo de problematização das gestões municipais numa perspectiva administrativogerencial.

Em relação ao debate mais conceitual sobre a estratégia a matriz teórica que prevalece nos trabalhos científicos é a critica, isso implica numa compreensão que articula os arranjos setoriais a fatores endógenos as políticas públicas, bem como a fatores exógenos, nomeadamente a questão da estrutura sobre a qual tais políticas se corporificam. Ademais, foi percebido que a totalidade dos trabalhos apesar de discutirem questões da dimensão da micropolítica, pauta suas análises nos fatores macro políticos.

No material analisado foi constatado que o mecanismo da intersetorialidade é investigado por grande parte dos pesquisadores a partir do cruzamento com as categorias de análise que seguem no quadro abaixo: 
Quadro 1 - Categorias mais utilizadas pelos autores para trabalhar a intersetorialidade

\begin{tabular}{|l|}
\hline Integralidade \\
\hline Interdisciplinaridade \\
\hline Setorialidade \\
\hline Totalidade \\
\hline Descentralização \\
\hline Territorialização \\
\hline Regionalização \\
\hline Proteção social \\
\hline Seguridade social \\
\hline Controle social \\
\hline
\end{tabular}

Fonte: primária

Como é possível verificar a categoria da integralidade é a principal articulação nas reflexões construídas. Isso se explica pelo fato de ser no campo da saúde onde se aglutinam a maioria dos trabalhos, também pelo fato da política da saúde tomá-la como estratégia no sistema de referência e contra-referência e por ser a integralidade um dos princípios fundantes do Sistema Único de Saúde.

Como postulam Mioto e Nogueira;

A integralidade é apreendida em várias dimensões, transitando da esfera político-administrativa para a esfera da atenção à saúde. Na esfera político-administrativa, diz respeito tanto à forma de organização dos sistemas e serviços de saúde, na perspectiva do atendimento nos níveis de atenção, como na integração com os demais setores e serviços disponíveis para a atenção integral à saúde. Na esfera da atenção à saúde, diz respeito tanto à relação entre a realidade social e a produção de saúde como à relação equipe-usuários dos serviços e ações de saúde, considerando a necessária integração de saberes e práticas. Em consequência, traz implícita a interdisciplinaridade e a intersetorialidade (Ibid., 2009, p. 9).

Outra categoria que se destaca no material analisado é a interdisciplinaridade, reforçando um consenso teórico a partir do qual, a estratégia da intersetorialidade em sua tessitura depende visceralmente da quebra do modelo cartesiano que caracteriza a produção do saber nos últimos séculos.

No entanto, Mendes e Arkeman advertem que; 
No campo da pesquisa científica eletrônica, nas bases lilacs e medline, ocorre uma luz nesse campo. Se "intersetorialidade" não é identificada como palavra-chave, há um conjunto de expressões correlatas ao tema: “ação intersetorial”, “cooperação intersetorial” e "coordenação intersetorial" que são reconhecidas e propiciam busca de artigos relacionados ao assunto. Talvez os indexadores estejam nos passando a mensagem de que mais do que interessados no conceito, eles queiram advogar a prática concreta no campo da intersetorialidade, ao privilegiarem palavras como "ação", “cooperação" e “coordenação" (2004, p. 54)

Em relação particularmente, aos trabalhos apresentados nas edições do ENPESS arroladas na pesquisa, identificamos um movimento crescente de interesse pela temática na medida em que, os arranjos intersetoriais passaram a fazer parte das agendas das políticas de proteção social, a exemplo das Políticas da Saúde e da Assistência Social, bem como das políticas por segmentos, como a da Criança e do Adolescente, Saúde Mental, Idosos.

Quadro 2 - Edições do ENPESS e frequência de trabalhos sobre intersetorialidade

\begin{tabular}{c|c|c}
\hline ENPESS & ANO & $\begin{array}{l}\text { QUANTIDADE DE TRABALHOS } \\
\text { RELACIONADOS À INTERSETORIALIDADE }\end{array}$ \\
\hline VIII & 2002 & 01 \\
\hline IX & 2004 & 00 \\
\hline X & 2006 & 02 \\
\hline XI & 2008 & 03 \\
\hline XII & 2010 & 09 \\
\hline XIII & 2012 & 14 \\
\hline
\end{tabular}

Fonte: Primária

Do mesmo modo, quando analisamos a frequência de trabalhos sobre a intersetorialidade nos periódicos investigados, identificamos que há um movimento crescente de interesse pela temática, sobretudo relacionado-as às políticas sociais, como é possível verificar no quadro que segue. 
Quadro 3 - Frequência de trabalhos sobre intersetorialidade em artigos científicos.

\begin{tabular}{|c|c|c|}
\hline $\begin{array}{c}\text { TRATAMENTO DA } \\
\text { INTERSETORIALIDADE }\end{array}$ & $\begin{array}{l}\text { QUANTIDADE DE } \\
\text { TRABALHOS } \\
\end{array}$ & $\begin{array}{c}\text { ANO DE } \\
\text { PUBLICAÇÃO }\end{array}$ \\
\hline $\begin{array}{l}\text { Trabalha a } \\
\text { Intersetorialidade atrelada } \\
\text { às Políticas Sociais }\end{array}$ & $\begin{array}{c}1 \\
1 \\
2 \\
6 \\
10 \\
\text { (total de 20) }\end{array}$ & $\begin{array}{l}2002 \\
2006 \\
2008 \\
2010 \\
2012\end{array}$ \\
\hline $\begin{array}{l}\text { Trabalha a } \\
\text { Intersetorialidade atrelada } \\
\text { ao Exercício profissional } \\
\text { do Assistente Social }\end{array}$ & $\begin{array}{c}1 \\
1 \\
3 \\
4 \\
\text { (Total de 9) }\end{array}$ & $\begin{array}{l}2006 \\
2008 \\
2010 \\
2012\end{array}$ \\
\hline
\end{tabular}

Fonte: Primária

Tais dados evidenciam que o Serviço Social tem se apropriado da temática de forma crescente, porém poucos estudos são provenientes de experiências profissionais, mas sim de pesquisas acadêmicas em ambos os veículos de socialização do conhecimento (ENPESS e periódicos). Isso reflete um distanciamento dos profissionais que estão na etapa terminal de operação das políticas sociais da reflexão teórica mais apurada, fato esse já assinalado na literatura do Serviço Social por Netto (1996); Pontes (1997); Iamamoto e Carvalho (2000); Iamamoto ( 2002, 2005).

\section{CONSIDERAÇÕES FINAIS}

A possibilidade de focar nosso olhar sobre a intersetorialidade nos fez perceber inicialmente, a evidente impossibilidade de desvendá-la em todas as suas nuances. Trata-se de um tema em claro processo analítico por várias áreas científicas, precisamente as que se relacionam a administração pública; sociologia; saúde coletiva.

Em relação ao objeto central deste trabalho, constatamos que a intersetorialidade ainda é demarcada por um discurso polissêmico. Há, no entanto, uma compreensão de que a intersetorialidade deve ser analisada em instâncias diferentes, pois em cada uma 
delas novas proposições insurgem, ou seja, na dimensão da formulação das políticas, na dimensão da gestão e na dimensão da execução ela incorpora elementos diferentes.

No conjunto de produções investigadas se identificam alguns consensos, tais como: a inexistência de modelos estáticos para sua aplicação; a relação íntima dela com a interdisciplinaridade de saberes; a necessidade de ambientes democráticos para sua efetivação; a trasversalidade de seu uso em conjunto com a integralidade de ações; sua potência na busca por efetividade e eficiência, sua similaridade com os processos sinérgicos e com a capacidade de articulação de atores e instituições.

Foi possível por outro lado, detectar alguns dissensos, predominantemente em relação às categorias de análises que auxiliam no processo de decomposição em que realmente consiste a intersetorialidade. Algumas produções a vinculam a setorialização, numa interpretação que a coloca como antagônica. Outras a tratam como dispositivo de gestão, algumas como tática, inserida, num processo de gestão com estratégias mais estruturantes como a descentralização.

Há na produção científica tanto no âmbito mais geral das ciências sociais aplicadas, quanto particularmente no Serviço Social, uma plêiade de conceitos e interpretações. Contudo, foi perceptível o fato de que a construção do Serviço Social acerca desta estratégia de gestão segue a matriz crítico-reflexiva, o que resulta numa produção eivada de articulações estruturais e conjunturais.

São produções em número massivo, que se debruçam sobre os problemas de gestão e resolutividade das políticas sociais em detrimento das iniquidades sociais, apontando as necessidade dos arranjos intersetoriais e ao mesmo tempo, as dificuldades que as políticas encontram ao tentarem um diálogo mais próximo. Outrossim, inferem a falta de planejamento estratégico e a forte conotação disciplinar que configuram tais políticas e seus planos, programas e projetos. No que se refere aos limites que se interpõe a prática do assistente social do campo da saúde na tessitura de arranjos intersetoriais a luz da produção teórica constante nos principais canais de circulação da produção científica do Serviço Social Brasileiro, foi possível identificar que os poucos autores que desde já enfrentam o desafio de discutir o tema, depositam na estrutura histórica que perfaz as políticas sociais brasileiras, um dos maiores obstáculos.

Dentre os poucos trabalhos que reconhecem na atuação profissional do assistente social uma relação direta ao estímulo, a provocação da intersetorialidade, se destacam as produções de Regina Mioto e de Maria Dalva Horácio, ambas com percepções bem semelhantes sobre a questão.

Serv. Soc. \& Saúde, Campinas, SP v.14, n. 2 (20), p. 187-210, jul./dez. 2015 ISSN 1676-6806 
A tese fundante dessas autoras é a de que apesar de construírem cotidianamente arranjos intersetoriais, o profissional de Serviço Social, acabou por "rotinizarem" (MIOTO, 2007), tais procedimentos não reconhecendo em suas ações tentativas em nível da micro-política de construírem a intersetorialidade. Particularmente no campo da política da saúde, ao tornar possível através de vários procedimentos teóricometodológicos, o acesso do usuário do SUS a outras políticas ele desencadeia um diálogo, um movimento de articulação com as demais políticas que podem produzir a integralidade almejada.

Recebido em 28.07.2015 - Aprovado em 30.10.2015

\section{REFERÊNCIAS}

ANDRADE, L. O. M. A saúde e o dilema da intersetorialidade. Tese (doutorado)

Faculdade de Ciências Médicas. Universidade Estadual de Campinas. São Paulo, 2004.

AMARAL. G. As ações intersetoriais na Atenção na Saúde na Alta complexidade: construindo marcos de referências para o exercício profissional dos assistentes sociais. 2007. 68 f. Trabalho de Conclusão de Curso (graduação em Serviço Social). Departamento de Serviço Social. Universidade Federal de Santa Catarina.

BRASIL, Constituição (1988). Constituição da República Federativa do Brasil. Brasília, DF: Senado Federal, Centro Gráfico, 1998. 292p.

BRONZO, C. L. Intersetorialidade, autonomia e território em programas municipais de enfrentamento da pobreza: experiências de Belo Horizonte e São Paulo. 2010. Disponível em: < www.ipea.gov.br> Acesso em 19 abr. 2014.

CFESS. Código de Ética Profissional do Assistente Social. Brasília: CFESS, 1993.

COSTA, A. M. et al. Intersetorialidade na Produção e promoção da saúde. In.

CASTRO, A.; MALO, M. (orgs.). SUS: ressignificando a promoção da saúde. São Paulo: Hucitec, 2006.

COSTA, M. D. H. da. Os elos invisíveis do processo de trabalho em saúde: um estudo sobre as particularidades do trabalho dos assistentes sociais nos serviços públicos de saúde nos anos 90. 1998. Dissertação de Mestrado (Serviço Social). Recife: PPGSS/ UFPE.

COSTA, M. D. H. da. Serviço Social e Intersetorialidade: A contribuição dos Assistentes Sociais para a construção da intersetorialidade no cotidiano do Sistema Serv. Soc. \& Saúde, Campinas, SP v. 14, n. 2 (20), p. 187-210, jul./dez. 2015 ISSN 1676-6806 
Único de Saúde. 2010. 261f. Tese de Doutorado (serviço Social). Recife: PPGSS/ UFPE.

IAMAMOTO, M. V.; CARVALHO, R. de. Relações Sociais e Serviço Social no Brasil. 13 ed. São Paulo: Cortez, 2000. 380 p.

INOJOSA, R. M. Sinergia em políticas e serviços públicos: desenvolvimento social com intersetorialidade. Cadernos Fundap, São Paulo, n. 22, 2001, p. 102-110.

INOJOSA, R. M. Intersetorialidade e a configuração de um novo paradigma organizacional. RAP, Rio de Janeiro 32(2): p.35-48, mar./abr. 1998.

INOJOSA, R. M. Sinergia em políticas e serviços públicos: desenvolvimento social com intersetorialidade. Cadernos Fundap, São Paulo, n. 22, p. 102-110 2001.

INOJOSA, R. M.; JUNQUEIRA, L. A. P.; KOMATSU, S. Descentralização e ntersetorialidade na Gestão Pública Municipal no Brasil: a experiência de Fortaleza. In. XI Concurso de Ensayos Del CAD El Tránsito de La Cultura Burocrática al Modelo de la Gerencia Pública: Perspectivas, Posiblidades y Limitaciones. Caracas, 1997. JUNQUEIRA, L. A. P. Descentralização, intersetorialidade e rede como estratégias de gestão da cidade. Revista FEA- PUC- SP, São Paulo, v.1, p. 57 - 72, Nov. 1999. LANZA, L. M. B.; CAMPANUCCI, F. da S.; BALDOW, L. O. As Profissões em saúde e o Serviço Social: desafios para a formação profissional. Katalysis, v. 15, n. 2, jul./dez., 2012, p. 212- 220.

MENDES, R; AKERMAN, M. Agendas Urbanas Intersetoriais em quatro cidades de São Paulo. Saúde Sociedade. v. 13, n. 1, 2004.

MONNERAT, G. L. Transferência condicionada de renda, saúde e intersetorialidade: lições do Programa Bolsa Família. 2009. 283 f. tese (Doutorado em Ciências na área de Saúde Pública). - Escola nacional de Saúde Pública Sergio Arouca/ ENSP. Fundação Oswaldo Cruz.

MIOTO, R. C. T.; NOGUEIRA, V. M. R. Serviço Social e Saúde - desafios intelectuais e operativos. SER social, Brasília, v.11, n. 25, p. 221-143, jul./ dez. 2009.

MIOTO, R. C. T.; NOGUEIRA, V. M. R. Política Social e Serviço Social: os desafios da intervenção profissional. Katalysis, v.16, número especial. Florianópolis, 2013. NOGUEIRA, V. M. R.; MIOTO, R. C. T. Sistematização, planejamento e avaliação das ações dos assistentes sociais no campo da saúde. In: MOTA, A. E. et. al. Serviço Social e Saúde: Formação e Trabalho profissional. São Paulo: Cortez; Brasília. OPAS, OMS, Ministério da Saúde, 2009, p. 88-110. 
PEREIRA, P. A. P. Como Conjugar especificidade e intersetorialidade na construção e implementação das políticas de assistência social. Serviço Social \& Sociedade. n. 77, São Paulo: Cortez, mar. 2004.

PEREIRA, P. A. P. A Intersetorialidade das Políticas Sociais numa perspectiva dialética. (mimeo). UNB, 2011

SCHÜTZ, F. A intersetorialidade no campo da política pública: indagações para o Serviço Social. 2009. 85 f. Trabalho de Conclusão de Curso (graduação) Departamento de Serviço Social. Universidade Federal de Santa Catarina.

SCHÜTZ, F.; MIOTO, R. C. T. Intersetorialidade na Política social: reflexões a partir do exercício profissional dos assistentes sociais. DIPROSUL. Pelotas, 2011.

SCHÜTZ, F.; MIOTO, R. C. T. Intersetorialidade e Política Social: subsídios para o debate. Sociedade em Debate, Pelotas, 16(1): 59-75, jan./jun. 2010.

SPOSAT, A. Gestão Pública Intersetorial: Sim ou Não? Comentário de experiência. Serviço Social \& Sociedade. n. 85, São Paulo: Cortez, mar. 2006. 